\title{
The Innovation for College Teaching Practice Based on PBL Model
}

\author{
Liao Yuanjiang ${ }^{1}$ Fan Jianbo' $^{1}$ Guo Fei $^{2}$ Li Jun ${ }^{1}$ \\ ${ }^{1}$ Ningbo University of Technology, School of Electronics and Information Engineering, \\ Ningbo, 315016, China \\ ${ }^{2}$ Shanghai Association for Continuing Engineering Education, Shanghai, 200070, China
}

\begin{abstract}
During the traditional college teaching practice, teacher talks a lot and imparts the knowledge to the students in the classroom. While the students are often passive listen and not well understand. Finally, the students get to remember some abstract mathematical formulas, the complexity of the laws. But it is difficult to use their in practical work at all. We teach the college course named process control system in a problem-based learning (PBL) model. It make students engage complex, challenging issues and collaboratively work toward their resolution. This paper illustrates with teaching paradigm.
\end{abstract}

Keywords: PBL Model, Professional Course, Classroom Experiences

\section{Introduction}

During the traditional college teaching practice, teacher often encounter the kind of problem: teacher on the podium to talk a lot and to impart the knowledge of the special discipline in the classroom. While the students are often not well understand. Finally, the students get to remember some abstract mathematical formulas, the complexity of the laws, but it is difficult to use their in practical work, or will not solve the practical problems in real life at all. Now, teachers need to take the advanced teaching theory and teaching methods, to design and innovation the teaching process. PBL model is the one of the advanced teaching theories that teacher can use effectively in all disciplines. PBL is about students connecting disciplinary knowledge to real world problems. The motivation to solve a problem together becomes the motivation to learn together.

\subsection{PBL Model}

Howard Barrows and his colleagues pioneered PBL in the medical school program at McMaster University in Hamilton, Ontario, Canada in 1960s [1]. The founders of PBL developed the PBL theory and experience. Howard Barrows and his colleagues proposed fundamentals for the curriculum, which included learning in small groups for the study of clinical issues. It made medical education more interesting and relevant for their students.

The most important differences between PBL curricula and traditional medical curricula are the learning environment. A PBL curriculum generally makes use of small group tutorials with a student-centered approach, active learning, the use of issues and a significant amount of time for independent study. Thus, students must discover or construct essential knowledge for themselves [2].

PBL aims at efficient acquisition and structuring of knowledge by active, selfdirected ways. Furthermore, PBL builds on prior knowledge integration, critical thinking, achieves its goals by small- 
group work and independent study, and relates to problem solving only in so far as knowledge becomes more accessible and can therefore be applied more efficiently during this process [3].

Now, PBL remains a valid and effective environment for education in a rapidly changing and challenging time for curriculum innovation [4].

\subsection{Discrepancy of Students' Learn- ing Level}

Only a few students can learn by himself in the area of his special disciplines. The other students rely on rote memorization and mechanical formula substitution. They are making little or no effort to understand the knowledge being taught. In such a case, teacher needs to adopt efficacious methods of teaching, explore the applicability of new model. It is necessary for students to get the highest grade they can by deep methods. If students do not have that kind of ability, teacher will take ordinary approaches that suffices and necessary. But, the purpose of education should be to induce students to adopt deep methods to his special disciplines which are very important for his professional and personal development. Advance students should be to that level by the time they graduate.

Teacher needs to organize students to discuss. Some of them display thinking patterns resembling an expert scientist or engineer. Let the "engineer" to play a principal or guiding role in learning.

The topic of discrepancy of students' learning level is discussed briefly in order to teach them effectively.

\section{Application Examples}

Now we teach process control courses by innovative practice of PBL Model. The teaching mode is specified issues by organizing students under the guidance of teacher. After a certain time of the prelearning and practice, students seek independent construct answers actively, to increase their ability in process of studying. Teacher encourages students to discussion, participatory teaching and learning, to stimulate students' curiosity. There will change the situation of indoctrinating the students with knowledge.

PBL teaching mode consists of two parts: (1) teacher implement the framework; (2) Students learning framework.

\subsection{Teacher Implement the Frame- work}

Teacher implements the framework as shown in Table 1. It includes: (1) The origin of particular subject knowledge and the ideas of implementation; (2) Design feasible students' learning framework according to the characteristics of disciplines and actual environment and conditions; (3) The resources and tools of teacher can use.

Table 1: Teacher's parts

\begin{tabular}{|l|l|}
\hline \multicolumn{1}{|c|}{ Design } & \multicolumn{1}{c|}{ Analysis } \\
\hline $\begin{array}{l}\text { Encourage students to speak, when students } \\
\text { give a presentation of what he study, he can use } \\
\text { the blackboard, slides and other auxiliary mate- } \\
\text { rials. To share knowledge and information; } \\
\text { Generate possible solutions. }\end{array}$ & $\begin{array}{l}\text { Teacher make students has a simple impression } \\
\text { about Cascade control system; } \\
\text { Learning objectives contained in the question } \\
\text { are the need to be understood and mastered by } \\
\text { all students. Teacher must aim at the key issues. }\end{array}$ \\
\hline $\begin{array}{l}\text { Cascade Control System: two controllers con- } \\
\text { catenated work together; the output of one con- } \\
\text { troller is the input of another controller. }\end{array}$ & $\begin{array}{l}\text { Teacher affirms the students' expression, and } \\
\text { supplements the critical information for stu- } \\
\text { dents have not expressed. Get the goal of teach- } \\
\text { ing objectives. }\end{array}$ \\
\hline $\begin{array}{l}\text { Solve the problem: } \\
\text { A five-minute discussion: how to select the }\end{array}$ & $\begin{array}{l}\text { Concentrates on clear explain; } \\
\text { Teacher guide students to comprehensive think- }\end{array}$ \\
\hline
\end{tabular}


main and auxiliary control law for the controllers in a cascade control system?

Teacher conclude the lecture by summing up and add: in the cascade control system, because of the introduction of a sub-circuit, not only can overcome to enter the sub-loop disturbance early, but also can improve the characteristics of control process. Auxiliary controller has the role of "coarse tune", and main controller has "fine tune"; it makes the control quality to further improve.

\subsection{Student Learning Framework}

Students learning framework including: (1) Issues scene; (2) Tasks for study; (3) The design of the learning process; (4) Resources and tools of learning.

One of the design issues:

The tubular heater is one of the devices commonly used in the industrial process. It is required that the temperature of the heated material (crude oil) is a certain value. If this temperature be controlled well, it will prolong the life of the tubular heater and prevent burn it out; on the other hand, it can ensure the quality of the distillation and separation later. In Order to control the temperature of the outlet of crude oil, it is natural to design some principles in accordance with the simple control system. It is considered select the outlet temperature of the heater for the controlled variable, the amount of heating fuel for the manipulated variable to constitute a simple control system. According to the temperature of the crude oil outlet changes to control the degree of opening of the fuel control valve, i.e. by varying the amount of fuel to maintain the temperature of the crude oil outlet, to maintain a predetermined value in the process.

At first glance, the proposal of the above control scheme is feasible and reasonable. It is included all of the temperature disturbance factors in the control loop. As long as the disturbance leads temperature to change, the controller can ing and students discuss by group to explore the control law of auxiliary controller and main controller. make the changing temperature back by operating the valve to change the flow of the fuel oil. However, as the matter of fact that production process's control quality of the simple control system is poor, there are large fluctuations in the outlet temperature of the crude oil, it is difficult to meet the requirements of production, especially when there are large fluctuations in the fuel pressure or the quantity of heat of the fuel oil of the heating tubular heater itself.

Please select a type of system from the following complex control system. The control task can be achieved: the cascade control system? Averaging control system? Feedforward control system? Ratio control system? split-range control systems? Selectively control system? Dual control system?

There is a table should students to fill in as shown in Table 2.

Table 2: The features of several complex control system

\begin{tabular}{|l|l|l|}
\hline \multicolumn{1}{|c|}{ types } & Feature & $\begin{array}{c}\text { Applicable } \\
\text { occasions }\end{array}$ \\
\hline $\begin{array}{l}\text { cascade control sys- } \\
\text { tem }\end{array}$ & & \\
\hline $\begin{array}{l}\text { Averaging control } \\
\text { system }\end{array}$ & & \\
\hline Ratio control system & & \\
\hline
\end{tabular}

Modes of organization:

- The students inquiry data, independent thinking;

- Fill out the Table 2.

Learning Resources: 
- Thomas E. Marlin. Process Control. Mc Graw Hill, 2000. etc.

Anther design issues:

- What is cascade control system?

- How to select the main and auxiliary variables in cascade control system?

- Why the main loop is the fixed set point control system and the subloop is the servo control system in the cascade control system?

- How to choose the main and auxiliary control law of the controller for the cascade control system?

There are some tasks should students to solve:

- To draw the typical block diagram of the general cascade control system;
- Write the electronic documents to answer the above questions.

Modes of organization:

Think independently before class teaching and discussion between teachers to classmates.

Learning Resources:

- http://www.jingpinke.net/curriculu $\mathrm{m} / \mathrm{show}$.asp?id=2740

\section{Teaching Feedback and Evaluation}

Teacher gives students a table as shown in Table 3 after the class, it help students to encourage himself to improve motivation for learning.

Table 3: Students self-evaluation form.

\begin{tabular}{|l|l|l|l|}
\hline \multicolumn{1}{|c|}{ item } & excellent & better & good \\
\hline I find some points of view and facts by myself & & & \\
\hline I put forward a number of learning issues & & & \\
\hline I use a variety of self-study resources & & & \\
\hline I fully consider the issue and help others & & & \\
\hline I feel there is a ability of self-learning & & & \\
\hline I am more willing to discuss issues with classmates & & & \\
\hline
\end{tabular}

\section{Conclusion and Future Work}

Students can improve their research skills and social skills by PBL. In addition, PBL demonstrates the benefit of working cooperatively.

We will combine PBL with CDIO which is initialism for Conceive-DesignImplement-Operate method for teaching.

\section{References}

[1] Neville AJ, Norman GR, "PBL in the undergraduate MD program at McMaster University: three iterations in three decades," Acad Med, pp. 370374, 2007.
[2] Willis, S.C., Jones, A., Bundy, C., Budett, K., Whitehouse C.R. and O'Neill P.A. "Small-group work and assessment in a PBL curriculum: a qualitative and quantitative evaluation of student perceptions of the process of working in small groups and its assessment," Medical Teacher, pp. 495501, 2002.

[3] Hmelo-Silver C, Duncan RG, Chinn CA, "Scaffolding and achievement in problem based and inquiry learning: a response to Kirschner, Sweller, and Clark," Educ Psychol, pp. 99-107, 2007.

[4] http://www.samford.edu/ctls/archives. $\operatorname{aspx}$ ?id=2147484112 